tends to be used to fit each case. This seems at odds with the rigid framework of the book.

I liked the chapter on quality assurance and the need to allow for innovation and imagination and to not be imprisoned by treatment protocols.

This is a very inclusive book and not easy to read. It could be useful as an overview of treatments in child psychiatry or as a reference for reading up on possible actions in certain situations. Although there is an extensive bibliography, it is almost all in German. My preference would be for a more straightforward textbook and a range of specialist texts for the detail.

Rachel Leheup Independent Child Psychiatrist, c/oThe Royal College of Psychiatrists,

17 Belgrave Square, London SWIX 8PG, UK

\section{Early-Onset Dementia: A Multidisciplinary Approach}

Edited by John R. Hodges. Oxford: Oxford University Press. 2001. 478 pp. $€ 75.00$ (hb). ISBN 0192630342

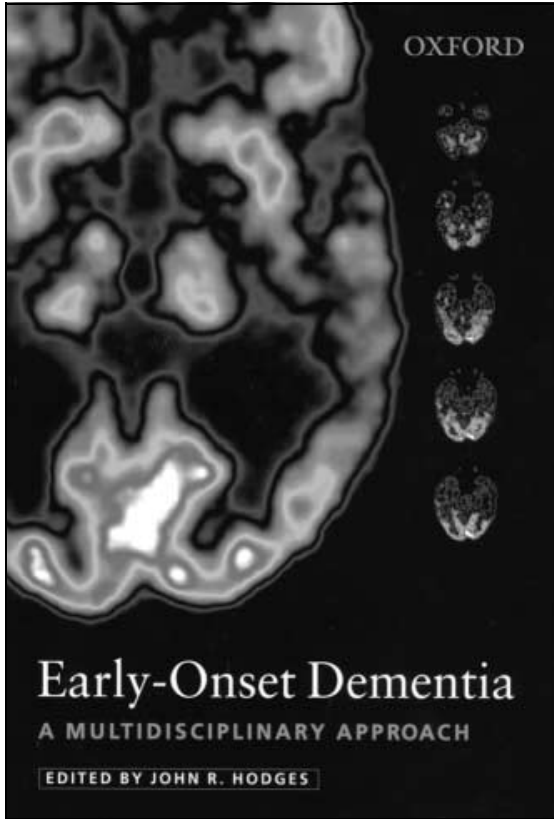

Early-onset dementia is an important area for clinical practice and research and tests the mettle and resources of both old age and general adult psychiatrists. The impact of early-onset dementia on sufferers and their families can be devastating. All the more reason to be practised and knowledgeable in approaching its diagnosis and treatment.
John Hodges's book consists of 20 multi-authored chapters on different aspects of early-onset dementia, from epidemiology through assessment and diagnosis to management. Each chapter ends with a number of key points. A comprehensive synthesis of clinical and basic aspects of early-onset dementia is presented. The reference list is comprehensive in relation to early-onset dementia as contrasted with Alzheimer's disease or dementia in general. The text is amply augmented by tables, images and illustrations. The chapter on clinical assessment and bedside tests is particularly useful. Other outstanding chapters are on neuropsychological assessment and neuroimaging.

The book does have some gaps. An area that I would like to have seen covered is the clinic model and how it works in a truly multi-disciplinary fashion. In this regard, Hodges refers us to another textbook but a critical appraisal of the Cambridge model and alternatives could have pointed providers setting up early-onset dementia clinics in the right direction. Also, a chapter on service provision beyond the memory clinic model and how we should be moving forward in this direction would have been helpful in informing opinion in this much neglected area. Carer burden can be extreme in early-onset dementia and some consideration of this topic and advice on management from a multi-disciplinary perspective would also have added to the value of the book.

However, this is a book that I expect to use regularly and profitably. I would recommend it to anyone with an interest in dementia and to those of us who work in memory clinics and continue to be challenged by our early-onset dementia cases.

Brian A. Lawlor Consultant Old Age Psychiatrist and Professor of Old Age Psychiatry, Jonathan Swift Clinic, St James's Hospital, Dublin 8, Ireland

\section{Eating Disorders and Cultures inTransition}

Edited by Mervat Nasser, Melanie A. Katzman \& Richard A.Gordon. Hove: Brunner Routledge. 2001. 201 pp. $€ 30.00$ (hb). ISBN $041522859 X$

The three editors of this interesting book are authorities on eating disorders and each

\section{Eating Disorders and Cultures in Transition}

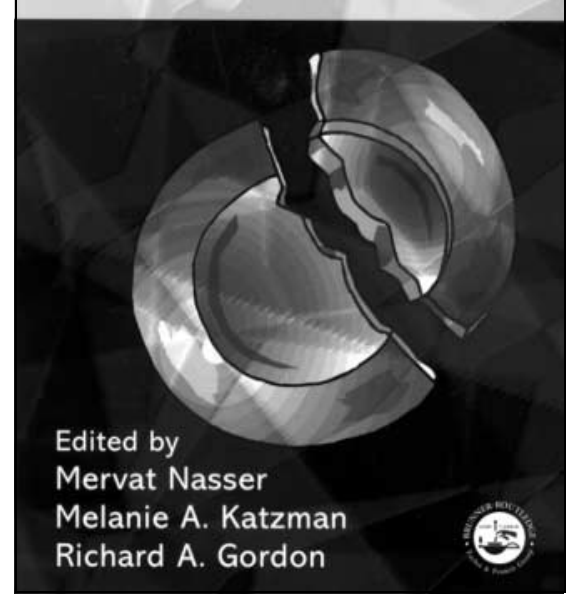

has wide experience of sociocultural issues. They bring together authors and perspectives from around the world to provide the cutting edge of opinion.

The book is organised into nine main chapters, each answering a different question. Each chapter is followed by two commentaries, one written by a clinician and the other by an expert from fields such as sociology, economics and anthropology. The purpose is to create debate about each of the questions posed. As none of the chapter authors had seen the responses before the book went to press, the views expressed in the chapters have not been influenced or altered by the commentaries. The use of commentators from widely differing disciplines is very thought-provoking and fosters involvement in the debate.

The questions posed are diverse. Topics include the notion of eating disorders as culture-bound syndromes, the recent emergence of eating disorders in Black South African women, the meaning of selfstarvation in China, as well as the possible political and economic meanings of the pursuit of thinness in Argentina. The identity struggle of women in changing societies is a recurring theme and is proposed as a possible factor in the increase in the incidence of eating disorders. However, there is little robust evidence with which to compare current levels of eating disorders, as most epidemiological studies on eating disorders are relatively recent.

Although many of the clinical accounts focus on local issues, they are surprisingly 